\title{
Teaching and learning social values: experience of resolution of conflicts in the classroom of physical education across the learning of social skills
}

\author{
MAR CEPERO GONZÁLEZ ${ }^{1}$, Ma NIEVES MARÍN REGALADO², JUAN TORRES GUERRERO ${ }^{1}$ \\ ${ }^{1}$ Faculty of Education, University of Granada, Granada, Spain \\ 2Primary School "Andres de Ribera". Jerez de la Frontera, Cadiz, Spain
}

\begin{abstract}
Cepero M, Marín MN, Torres J. Teaching and learning social values: experience of resolution of conflicts in the classroom of physical education across the learning of social skills. J. Hum. Sport Exerc. Vol. 5, No. 3, pp. 497-506, 2010. The main aim of this study has been the application of a sport and social program intervention to solve the daily problems of conviviality in the classroom of physical education, based on the teaching and learning of social values, attitudes and social skills. 24 children between 9-12 years of Guadix (Granada) have taken part in this study, learning social values that allow them to improve the social relations with their mates. In the data collection of information, three instruments were used; an initial and final sociogram (pre-post) was carried out with the objective of know the social relations of the group; two group interviews, in which the students talked about their learning process and the diary of the teacher, in which the teacher analyzed the program and the advance of the students. The results of three used instruments were compared, the analysis of data shows that there had been considerable changes in the attitude of the students, therefore the personal conflicts that were frequent to the beginning of the research, were diminishing in a gradual way along the experience. The students and the teacher showed their satisfaction for the improvement of their social skills and relationships through the sport motor learning.

Key words: LEARNING, EDUCATION, SOCIAL SKILLS, VALUES, ATTITUDES, AUTO ESTEEM, FRIENDSHIP.

Corresponding author. Facultad de Ciencias de la Educación, Campus La Cartuja s/n, Universidad de Granada, 18071 Granada (Spain).

E-mail: mcepero@ugr.es

Submitted for publication July 2010.

Accepted for publication September 2010.

JOURNAL OF HUMAN SPORT \& EXERCISE ISSN 1988-5202

(c) Faculty of Education. University of Alicante

doi:10.4100/jhse.2010.53.20
\end{abstract}




\section{INTRODUCTION}

Traditionally, teachers and educational planners have tended to conceptualise ability in sport as unitary, genetically inherited and measurable (Eyre, 1997; Kirk \& Gorely, 2000). They continue to believe that it is possible to define a child's level of ability by the use of a test and to give it a numerical score. Perhaps this is because traditionally the causes of learning deficit have been identified through the use of tests, or perhaps it is simply part of an unrealistic search for an ideal way to categorise children (Bailey, 2001).

Contemporary theorists almost universally favour multi-dimensional models of high ability (Baker \& Holton, 2004), cognisant of a wide range of factors. In devising a model of talent development in physical education, we were therefore mindful of the following:

- The model should be cognisant of the multi-dimensionality of abilities

- It should differentiate between potential and performance

- It should acknowledge the range of factors that can impact upon an individual's development of an ability; and, to return to a point made in the introduction

- It should focus on physical education, per se, rather than related, but distinct concepts, like sport

- Physical education is a powerful way for increasing social skills

Physical education can contribute to a wide range of recreational and career outcomes, and among the most important of these, we suggest, is lifelong physical activity and a way of socialization (Freeman, 2000). In striving to meet individual needs, an effective talent development programme should strive to maintain students' engagement with the subject so that, on leaving formal schooling, individuals take with them a lifelong commitment to physical education, and the activity areas that make it up.

The worries of the professorship for improving his/her educational practice, as well as his/her worry for solving the daily problems of lack of respect among mates and teachers, scanty responsibility and lack of auto esteem, there has led him to planning and applying a program of intervention motive partner based on the motive game (preferably cooperative) and on the corporal expression.

After the application of this program, it is hoped improve the relational aspects of the students with an enrichment of his attitudes and values that will reverberate in the improvement of the conviviality in the classroom.

The children and girls in school age in many occasions possess difficulties to do friendship, because in the form of current life, especially in the cities, there do not take place many occasions to establish relations out of the school area. The physical activity is a suitable way to create social healthy relations is, for the conditions of the tasks carried out, there are created bows of companionship, motivation, increase of the auto esteem since in her there is established great quantity of attitudes and values.

This paper presents a model of social education in physical education, drawing together different tools of measuring social values acquisitions. In presenting this model, the authors aim to redress the imbalance within the current debate from an almost total concern with out-of-school clubs and the preparation for adult sport, in favour of a more equitable and inclusive approach, curricular physical education within any sport talent development scheme but a high development in social values. 
The main aim of this study has been the application of a sport and social program intervention to solve the daily problems of conviviality in the classroom of physical education, based on the teaching and learning of social values, attitudes and social skills.

\section{MATERIAL AND METHODS}

\section{Participants}

The environment where the investigation has developed has been the Region of the Oriental Mounts, Guadix's zone (Granada) and the participants have been 24 children and girls between 9 and 12 years, which have received two weekly hours of class in the first pedagogic time, for 8 months. To the group of 9 10 years we called group of $4^{\text {th }}$ and to the children and 11 and 12-year-old girls we called them group of $5^{\text {th }}$.

\section{Instruments}

For the checking of the efficiency of the program of intervention the following instruments have been in use: a sociogram at the beginning of the research (pre) and at the end (post), two interviews (groups of discussion) once finished the experience and the diary of the teacher along the whole process.

\section{Independent variables}

There are many values involved in our investigation, but in that we have centred our attention are the respect, the responsibility, the auto esteem and the friendship.

Respect

According to Collado (2005) "it is necessary to help to construct an ethics for the conviviality, which allows the student body to be unrolled in the current company and to develop the necessary skills in order that they could auto construct and reconstruct, along his/her lives, his/her code of ethics".

With this value, there is claimed that the student body is capable of learning to relate to the others, respecting the ideas of each one, his/her way of being, of acting and his/her physical possibilities, that is to say to act of collaborative and solidary form promoting the scout, respecting the procedure and the school materials. There is promoted that the student body was developing attitudes as the cooperation and the tolerance valuing the importance of a pacific conviviality between student body of different sexes, races and cultures.

This value induces to the dialog as way to solve the troubled situations and is the fundamental base of a good conviviality, the lack of respect, is the consequence of the violence and of the intolerance.

Responsability

The responsible person seeks to give a suitable and respectful response to every reality, to every situation, is capable of choosing and deciding, of decisions being kept in his and takes charge of his consequences.

The responsible student body is employed at collaboration with the companions and companions. To form in the responsibility is precise to know that: that they all can contribute something valuable and that the competitive situations do not help the learning and that the cooperatives are more suitable for the teaching and learning process. 


\section{Auto esteem}

The auto esteem is the concept that we have of our personal value and of our capacity. It is, therefore, the sum of the auto confidence, the feeling of the own competition and the respect and consideration that we us have to us, Collado (2005).

With this value we look that the student body is known likewise, value the positive aspects of his/her personality and scorn the negatives, in such a way that he thinks that it possesses more aspects positive that negative. In this respect, we claim in our classroom:

- To distribute the protagonist in the classes.

- To do that the students perceives their achievements.

- $\quad$ To use the positive reinforcement.

- $\quad$ To promote the positive comments among the students.

- To introduce games and specific dynamics.

\section{Friendship}

At the social level, it is evident that the physical - sports activities practised in group, increase the formation of the character and the integration in the company of the children since, in most cases, it increase the social links, the cooperation, the decision, the courage, etc. To be friends means a step improving the conviviality, to be able to share, the affectability in supreme degree, it generates well-being. The activity in the classroom makes possible that the affections experience a high degree of empathy, of sharing, of cooperating and definitively the classes of physical education promote the friendship between those who practise it.

A definition of what we consider to be social skills was given by Vallés (1995) "the form, in which we relate to the others, is our behaviour, the form in which we say the things. The learning of the same ones centres on the auto esteem and the solution of problems, they try that the children know themselves, and have a better valuation of themselves".

It is known well that the learning of the above mentioned skills, they are going to use as strategies to learn and relate with others, in such a way that the conflicts are avoided and increasing the fluency in the relations. The social skills that this research is reaching are:

- Skills related to the auto esteem: to be positive, not to be aggressive, not liabilities; to look for solutions to the problems; not to lose hope if the things are not ok, to look for the positive thing. To accept the skills of conversation: to initiate conversations; to support conversations; to finish conversations; to show attitudes of scout; not to realize gestures that trouble; to take care of the intonation, to express the complaints with education; to say "not" when it is convenient; to defend the own rights.

- Skills to be employed at group: to know the members of the equipment; to know his/her interests of each mate; to participate with the group; to establish procedure; to listen what the others count: bear the opinions in mind of all and all; to give ideas; to share; to collaborate with your friends; skills to solve conflicts: to discover the feelings of the others before the conflict; to understand the others; to respect the ideas and attitudes; to try that the others understand us; to be nice; to ask for excuses; to look for solutions; to avoid the conflicts to avoid thought inadequate of the others. 
- Skills of responsibility: to full fill the commitments; to try that the things go out the possible better thing; not to harm the others; to ask for excuses if one cannot stand involuntarily to anybody; to praise the one who is responsible; to avoid the exaggerate requirements; to understand how the others feel.

- Skills of respect: not to stick, to push, and not to allow that they should stick and push us, but without attacking; not to insult and not to allow that they should insult us; not to intimidate the others; not to ridicule anybody; to play with all and not to stop out of I play nobody; not to fight; to respect the things of the others; not to bother anybody; not to call the attention (spitting, lying, speaking about bad manners or provoking, to do noises and not to stop working to the others, to throw the fault to others of the bilges that are done); not to get angry; not to get with the others, to avoid the heavy jokes; to avoid the verbal disqualifications; to avoid the physical aggressions; not to give from side to nobody.

\section{Program of Intervention}

The program consists of eight didactic units, in the area of Physical Education, which they have been applied between November to June, with different timing with a two to three weekly meetings of work, depending of the months and begun by the didactic unit "our rules", with an exposition of aims and general contents, to continue with the most specific development of seven didactic units of character and to be able like that to come together in the attainment of the didactic aims that we have appeared. The units have been:

- Didactic unit: our rules

- Didactic unit: who am I?

- Didactic unit: been charmed with of knowing yourself

- Didactic unit: let's play at trusting.

- Didactic unit: all the equal ones, all the different ones

- Didactic unit: without opposite

- $\quad$ Didactic unit: my body expresses and communicates

- Didactic unit: resolving problems among everybody

\section{The Sociogram}

Rodríguez and Morera (2001) think that the sociogram is a sociometric technology to determine the preferences of the individuals I concern diverse persons who form a part of his way.

It is an instrument that explores the degree of cohesion and the form of structure hospitalizes of the relations that exist among each and every of the individuals who compose a group. Basically, it facilitates the vision of the global one of the structure of the group and indicates the relative position of each one of the members. It consists of a series of questions formulated to every member of the group, in order that he writes other members of the group that it would choose and / or reject for a set of tasks, and choose the leadership, the rejection, the relations you reciprocate, definitively the relations.

The punctuations are obtained from bearing certain formulae in mind, bearing in mind that will give himself a punctuation of 3 to the first choice and of 2 to the second choice, according to the number of repetitions: For example; to determine the one who is the leader or leaders of the group, the popularity is in use the formula (Sp/N-1) being $\mathrm{Sp}$ the sum of all the repetitions and $\mathrm{N}-1$ the sample less one. 


\section{Group of discussion and interviews in group}

The group of discussion is a qualitative technology, very similar to the interview, where there appears a plot line directed by an interviewer or moderator, but orientated to a group of persons, who are going to debate this plot line. It might indicate to him that "the groups of discussion constitute a modality of interview in group" (Monjas \& De la Paz, 1998).

A group of discussion is a persons' meeting, among six and ten, that speak about a topic under the direction of another person" (Callejo, 2001). Due to the fact that the participants in the group already knew themselves and the relations were distended and even of friendship and confidence and they share same classroom, of there that also we have named to the technology used "interview in group".

With regard to the design of both groups of discussion it was keep in mind: the characteristics of the participants, members of the group were mates of class, they had been also in the previous course and in such a way that confidence existed, from the beginning. It was not necessary to realize several introductory meetings in order that they were known. Due to the fact that the participants in the group already knew themselves a session of discussion appeared for the children and 9-10-year-old girls and other one for the children and girls of 11-12, to which they came without a previous knowledge detailed of the agenda, in such a way that they were not taking predetermined ideas. More meetings were not realized to avoid the redundancy in the discussion.

In order that the information acquires a meaning, it had to be submitted to an analysis. The phases for which the information has happened have been the following ones:

- Transcription

- Treatment in the software AQUAD five. Version 5.1

- Classification in relevant categories

- Description

- Interpretation

\section{The Diary of the Teacher}

The diary was a personal document of great usefulness for researcher. Since it allows, by means of the record and the descriptions that it realizes on the experiences lived in the classroom, to think, be aware of his/her actions and of acquiring a practical knowledge across the decisions that he/she adopts for future interventions. On the other hand, the diary provides information to the assessor of the thought of the teacher in the process of education - learning and what it has annotated on his/her practice: anecdotes, feelings, attitudes, motivations, perceptions on the elements of the curriculum, of the context, of the pupils, personal conclusions on having reacted in the development of the meetings (problems and opposing difficulties), events. All that will facilitate information continued to the teacher - investigator on his/her difficulties and needs needed as consequence of the practical experience, adopting the orientations and opportune reflections to improve his/her own professional development.

\section{RESULTS AND DISCUSSION}

By means of the application of the tests (November and June), we could verify which were the real reasons of the conflicts and that pupils were those who were generating them in a widespread way.

For the triangulation, process in which there are confirmed all the results of the technologies used in the research; we have chosen the analysis of the response of June. 
In the group of $4^{\text {th }}$, we verify that the student body chosen by the rest of his companions / aces it was: $R$ with a punctuation of 21, it was following him $\mathrm{J}$ with $12 ; \mathrm{C}$ with 6 and to with 5 , and in the group $5^{\text {th }}$ was $P$ with a punctuation of 18 , was still JF with a punctuation of 11 and $\mathrm{JJ}$ with a punctuation of 9 . This way, almost the whole student body was coinciding with their choices, for what it was possible to deduce that pupils were the troubled; also I investigate on that type of aggressions were the most frequent in the classroom, for it there was requested that was arranging different types of aggression, depending on his/her criterion as for the gravity and the frequency with which the above mentioned episodes happened in the class. The results of the above mentioned arrangement it was established of the following order: the verbal insult first, followed by the rejection and finally the mistreatment (fundamentally physical).

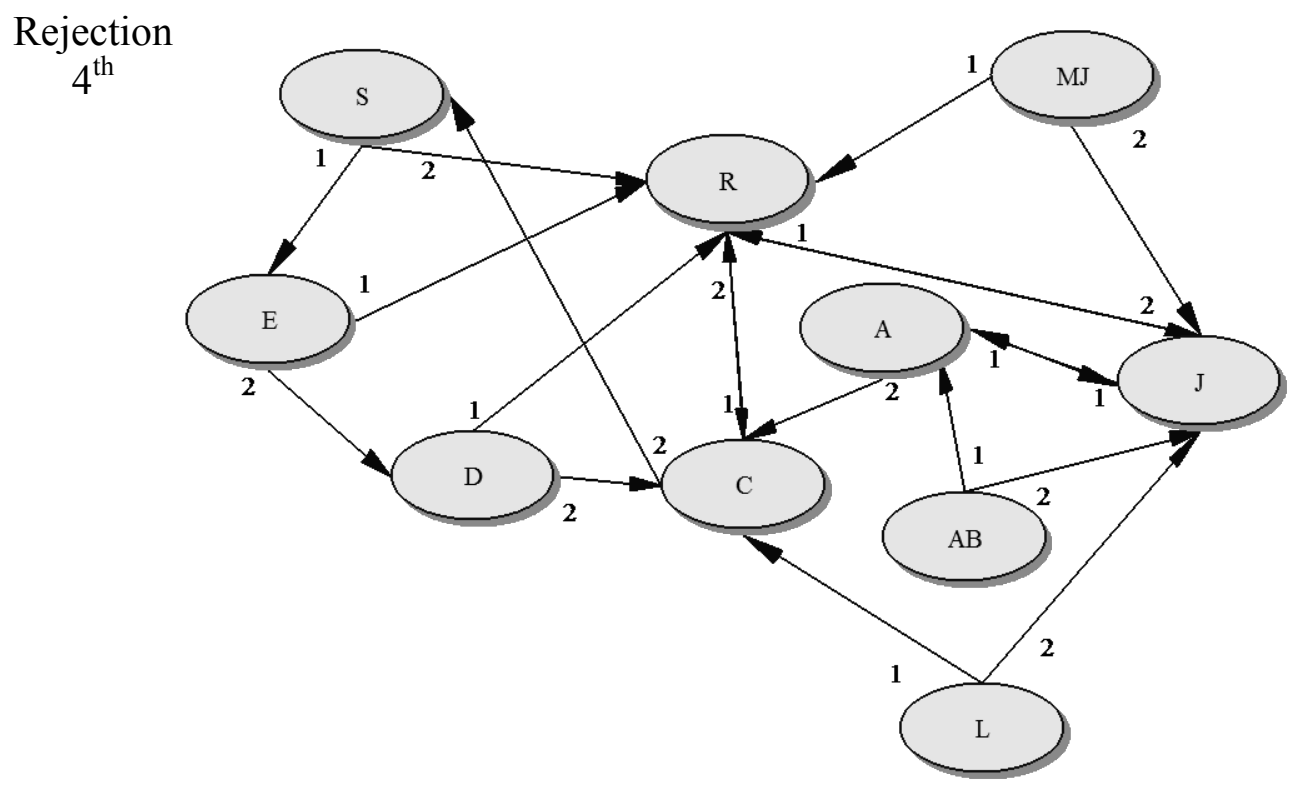

Figure 1. Scheme sociometric test.

Summarizing the results, we can establish that the insult was the first agent of conflict; this factor was corroborated in the Group of Discussion of the students in the one that demonstrates that to insult and to be ridiculed publicly or that the expectations of our role change into certain comments.

The excessive importance that gives him to the body, not to have a canon of beauty established or not to assume the individual differences, they can be tension reasons on the part of them and of verbal abuses on the part of others.

Another reason of verbal aggression they are the relations boy - girl, especially to the boys who relate to girls, it is a difficult challenge of overcoming, as well as the influence of the thoughts machists of the past.

To verify these possible differences they were interrogated it brings over of if it was important for them to realize pairs or mixed groups. 
The reflections established in the Diary of the Teacher, coincide with the information deduced of other two technologies of withdrawal of information; this way one demonstrates that the verbal aggressions are of the most frequent, but also episodes are described where the physical aggressions also are present.

Other reasons of conflicts, exposed in the Groups of Discussion with the student body, were the following ones:

- The difficulty to assume that there can be other mates, who differ from his/her criteria, impedes the possibility of carrying out a common assignment and to be respected without need to take always the reason.

- Another source of conflicts has been to lose the absolute possession of the friendship of a mate, not to overcome the egocentrism of having "an alone friend for me", in these ages the value of the absolute loyalty and the difficulty of learning the concept of which the friends or mates can be shared, is a concept difficult to acquire.

Across the Groups of Discussion we can verify which have been the advances in the learning of the social skills to solve conflict, across the utilization of way increasingly frequent of the following strategies:

- Talking, to learn that the dialog is the best way of solving a conflict has been someone of the multiple skills acquired by the student body.

- Showing respect and excusing. The respect is the base of any conviviality in company. The majority they have learned to ask for pardon and it does not have disadvantage in asking for it when he has been wrong, propitiating hereby the resolution of the conflicts.

- Mediation of the professorship. The student body has learned that another skill to solve conflicts is the mediation of an adult. In these cases they are the teachers who try to restore the harmony in the conducts of the students.

In summary, we can say that the reasons of the majority of the conflicts between the children and girls of $4^{\text {th }}$ and $5^{\text {th }}$ have been: the insult, the being ridiculed publicly, the physical aggression, not acceptance of the reasons or criteria different from the others and almost exclusive of the friendship.

As social skills that have been revealed and have been internalized, the students showed: the dialog, the attitudes of respect, the request of pardon before the own mistakes and the mediation of teachers for the resolution of the conflicts.

\section{CONCLUSIONS}

This program composed by eight didactic units that have included contents, from the corporal knowledge, to the expression of his/her emotions and to the collaborative relation among the participants, has affected in a positive way in the children and girls of the experimental group, as well as in an improvement of the relations of friendship among the students. As for the personal and group conflicts with episodes of antisocial behaviour that were abounding to the beginning of the investigation, they have been diminishing in a gradual way along the experience.

The students had begun to respect and to be accepted to one itself to learn to respect the others. And it is that in education there are no magic formulae, nothing happens at random, but the progresses and the improvements in the students is thanks of the programmed and systematized work, as well as good models provide to imitating. 
The real reasons analyzed in the group it brings over of the generation of the conflicts, they were the physical aggressions derived from the insult and was recognizing as the first agent of conflict, which in the majority of the occasions they were arising from daily situations in the classroom.

The relations among different kinds were reasons of conflict, especially to be ridiculed publicly for being different and not attending to the norm or rules established of beauty, as well as to give excessive importance to the body, it was another reason of discussion between the students, but after the learning of social skills, the promotion of the auto esteem and the precise respect to assume the individual differences has managed to evade the verbal abuses on the part of certain pupils.

The students of this research had learned social skills to solve conflicts, such as the dialog, to show respect, to ask for pardon when they have been wrong and in case of needing help to come to an adult as mediator, have been some of the multiple skills acquired by the student body.

The students has learned that the friendship is one to share affections, a feeling that encourages to be given and giving, receiving and understanding other one, not for pure interest. Across the relation with the others, of the common shared tasks, the student body has learned to discern critically the conducts, beliefs, procedure and values estimated by the group to which it belongs and compromises itself with the group in a relation of constructive exchange. A substantial change has taken place in the conduct of the students as for the acceptance of the least skilful mates to create teams; they accept the mates of the teams, without having to look for his/her real friends.

The program of intervention had collaborated in an effective way in the elimination of complexes, inhibitions and reviews the students first collective activities of the course, which had increased of the levels of auto concept and auto esteem. The cohesion of the group, as well as total integration of all the members of the group and the acceptance without any type of discrimination, has been reached with the application of the program of intervention.

\section{REFERENCES}

1. BAILEY RP. Teaching physical education: a handbook for primary and secondary teachers. London: Kogan Page; 2001. [Back to text]

2. BAKER J, HORTON S. A review of primary and secondary influences on sport expertise. High Ability Studies. 2004; 15:211-228. doi:10.1080/1359813042000314781 [Back to text]

3. CALLEJO J. El grupo de discusión: introducción a una práctica de investigación. Barcelona: Ariel Practicum; 2001. [Back to text]

4. COLLADO FERNÁNDEZ D. Transmisión y adquisición de valores a través de un programa de Educación Física basado en el juego motor, en un grupo de alumnos/as de primero de Educación Secundaria Obligatoria. Doctoral Thesis. Universidad de Granada; 2005. [Back to text]

5. EYRE D. Able children in ordinary schools. London: David Fulton Publishers; 1997. [Back to text]

6. FREEMAN J. Families, the essential context for gifts and talents. In: K. A. Heller, F. J. Monks, R. Sternberg \& R. Subotnik (Eds.). International handbook of research and development of giftedness and talent. Oxford: Pergamon Press; 2000. Pp. 573-585. [Back to text]

7. KIRK D, GORELY T. Challenging thinking about the relationship between school physical education and sport performance. European Physical Educational Review. 2000; 6:119-134. doi:10.1177/1356336X000062002 [Back to text]

8. MONJAS MI, DE LA PAZ GONZÁLEZ B. Habilidades sociales en el currículo. CIDE. Centro de Investigación y Documentación Educativa. Ministerio de Educación y Ciencia; 1998. [Back to text] 
9. RODRÍGUEZ A, MORERA D. El Sociograma. El estudio de las relaciones informales en las organizaciones. Madrid: Pirámide; 2001. [Back to text]

10. VALLÉS ARÁNDIGA A. Programa de refuerzo de las habilidades sociales I. Cuadernos de recuperación y refuerzo de planos psicoafectivos. Madrid: Método EOS; 1995. [Back to text] 